\title{
Effects of Hydrocarbon Addition on Increase in Dilatation of Coal
}

\author{
Hideyuki HAYASHIZAKI ${ }^{1,2) *}$ Koji KANEHASHI, ${ }^{1)}$ Kazuya UEBO, ${ }^{1)}$ Seiji NOMURA, ${ }^{1)}$ Yasuhiro SAITO, ${ }^{3)}$ \\ Yohsuke MATSUSHITA ${ }^{2)}$ and Hideyuki AOKI ${ }^{21}$
}

1) Research \& Development, Nippon Steel \& Sumitomo Metal Corp., 20-1 Shintomi Futtsu, Chiba, $293-8511$ Japan.

2) Department of Chemical Engineering, Graduate School of Engineering, Tohoku University, 6-6-07, Aoba, Aramaki, Aoba-ku, Sendai, Miyagi, 980-8579 Japan.

3) Department of Applied Chemistry, Kyushu Institute of Technology, 1-1 Sensui-cho, Tobata-ku, Kitakyushu, Fukuoka, 8043301 Japan.

(Received on January 16, 2019; accepted on June 17, 2019)

\begin{abstract}
The addition of coal tar pitch mainly composed of polycyclic aromatic hydrocarbons (PAHs), increases the dilatation of coal. We investigated the effect of PAHs on the maximum dilatation (MD) of hard coking coals and semi-soft coking coals. Twenty-six kinds of PAHs and aliphatic hydrocarbon were used as additive agents.

The use of a PAH with a molecular weight in the range 152.19-178.23 as an additive agent almost unchanged the MD. When a PAH with a molecular weight in the range 178.23-378.47 was added to the coal, the MD of the coal increased. The increase in MD achieved with the addition of 9,10-dihydrophenanthrene was larger than that obtained with the addition of phenanthrene. This is likely because the hydrogen atoms in the ninth and tenth positions in 9,10-dihydrophenanthrene inhibit the polymerization of the coal structure. The MD was hardly affected by the addition of a linear aliphatic hydrocarbon $\left(\mathrm{C}_{28} \mathrm{H}_{58}\right)$ but MD decreased due to the addition of anthraquinone with carbonyl carbon. When a PAH with nonplanar structure was added to the coal, the increase in MD was smaller than when a PAH with planar structure was added.
\end{abstract}

KEY WORDS: coal; metallurgical coke; dilatation; coal tar pitch; polycyclic aromatic hydrocarbon.

\section{Introduction}

High-strength coke is required to perform blast furnace operations with high productivity and low reducing agent ratios because coke sustains the permeability of gas and liquid. Although hard coking coal can produce high-strength coke, its price increases and its reserves decrease. Thus, we need to develop a technique to produce high-strength coke from a large quantity of semi-soft coking coal (i.e., lowquality coal).

Coke is a porous material, and its strength is affected by two factors, namely, the physical properties of the coke matrix and its defects. ${ }^{1)}$ With regard to the physical properties of the coke matrix, previous researchers have measured the elastic modulus of the coke matrix using the nanoindentation method by eliminating the effects of defects. ${ }^{2,3)}$ They indicated that coke produced from hard coking coal was not very different than that produced from semi-soft coking coal in terms of the elastic modulus of the active component of the coke matrix. ${ }^{2,3)}$ In general, the strength of coke obtained from hard coking coal is higher than that produced from semi-soft coking coal. Thus, the coke strength would be more affected by the defects generated in the

* Corresponding author: E-mail: hayashizaki.3hd.hideyuki@jp.nipponsteel. com

DOI: https://doi.org/10.2355/isijinternational.ISIJINT-2019-033 coke than by the physical properties of the coke matrix. In another previous study, the elastic moduli of the coke matrix before and after solution loss reaction were measured, and the stress analysis of a coke model generated by imagebased modeling of the optical microscopic images of coke was performed. ${ }^{4,5)}$ The researchers suggested that changes in pores have a stronger effect on the stress distribution than do variations in the elastic modulus of the coke matrix due to the solution loss reaction. ${ }^{4,5)}$

Cracks and pores are defects in coke and affect the coke strength. ${ }^{1)}$ In particular, micro-cracks of the order of millimeters were thought to influence coke strength and be caused by the difference between contraction coefficients of inertinite and vitrinite in the coke matrix. ${ }^{6)}$ Kubota et al. indicated that coke strength decreased with an increase of the size of inertinite blended. ${ }^{6}$ When a packed bed of coal particles was heated in a coke oven, pores were formed between the coal particles during the softening and dilatation of coal. After the coal particles were charged into the oven, the coke layer was immediately formed around the packed bed and inhibited the dilatation of the entire packed bed. Arima and Sakurai revealed that heated coal particles dilated, filled voids between particles, and adhered to each other. ${ }^{7)}$ When the dilatation of coal was sufficiently high, the coal particles completely filled the voids between particles and adhered to each other on all the surfaces. On the other hand, when the dilatation was low, the voids were not filled, 
resulting in adhesion failure (i.e., non-adhesion grain bound$\operatorname{aries}^{8)}$ ) in the coal packed bed. At this time, the dilatation behavior of the coal particles was not constrained by heating wall, and the coal particles freely dilated. Subsequently, the thin film around the particles burst and led to the formation of connected pores. ${ }^{8)}$ Thus, adhesion failure and connected pores can function as defects and decrease the strength of coke. Based on the above research, the dilatation of coal is thought to be an important factor affecting the strength of coke, and therefore, it is needed to develop a technique to increase the dilatation of coal.

It is known that the caking properties of coal, such as dilatation and fluidity, are increased by the addition of coal tar pitch, ${ }^{9,10)}$ asphalt pitch (ASP), ${ }^{10-12)}$ solvent refined coal $(\mathrm{SRC})^{13,14)}$ produced by thermally reacting coal with hydrogen solvent, hyper-coal, ${ }^{15)}$ and extracts from coal. ${ }^{16-18)}$ Among these additives, coal tar pitch is used as an industrial binder for briquetting ${ }^{19)}$ and is known to consist of various components such as polycyclic aromatic hydrocarbons (PAHs). ${ }^{20)}$ In the previous study, changes in the fluidity of coal were investigated when several hydrocarbon reagents were used. For example, polycyclic aromatic hydrocarbons, ${ }^{21)}$ aromatic hydrocarbons containing nitrogen, ${ }^{21-24)}$ and aromatic hydrocarbons containing oxygen. ${ }^{21,25)}$ These investigations revealed that the fluidity of coal increased when a PAH with a high boiling point or an aromatic hydrocarbon containing nitrogen was used, but decreased when an aromatic hydrocarbon containing oxygen was used. It is also known, on the other hand, that the fluidity of coal increased substantially with the addition of a material with a low softening point, such as straight asphalt (softening point $46.0^{\circ} \mathrm{C}$ ) and propane deasphalting asphalt (softening point $77.3^{\circ} \mathrm{C}$ ), but dilatation did not increase considerably. ${ }^{9}$ ) Therefore, although the addition of coal tar pitch increased the dilatation of coal, little is known about the components of coal tar pitch contributing to the increases in the dilatation of coal.

If it is possible to identify the effective component among additives for increasing the dilatation of coal and to clarify the mechanism of interaction between the hydrocarbon reagent and coal, high-performance additives can be produced. Furthermore, by using high-performance additives, high-strength coke can be produced even under a condition that a large amount of semi-soft coking coal is blended. In the present study, the dilatation of coal with hydrocarbon reagents was measured to identify the hydrocarbon contributing to the increase in the dilatation. Furthermore, to investigate the interaction between the hydrocarbon reagent and coal, the decrease in the weights and the changes in the infrared (IR) spectra of coal with hydrocarbon reagents were measured using thermogravimetric analysis and a hightemperature IR spectrophotometer system, respectively.

\section{Experimental}

\subsection{Samples}

Table 1 lists the properties of the coals used as samples. Coal A and Coal B were hard coking coals, and Coal C was semi-soft coking coal. The hydrocarbon reagents used are listed in Table 2. Their structural formulae are shown in Fig. 1. Twenty-six kinds of hydrocarbon reagents with a molecu-
Table 1. The properties of the coals used as samples.

\begin{tabular}{ccccccc}
\hline & \multicolumn{2}{c}{$\begin{array}{c}\text { Proximate analysis } \\
\text { Coal }\end{array}$} & \multicolumn{2}{c}{$\begin{array}{c}\text { Petrographic } \\
\text { analysis }\end{array}$} & \multicolumn{2}{c}{ Dilatometry } \\
\cline { 2 - 7 } & Ash & $\begin{array}{c}\text { Volatile } \\
\text { Matter }\end{array}$ & $\begin{array}{c}\text { Total } \\
\text { inerts } \\
(\%)\end{array}$ & $\begin{array}{c}\text { Reflactance } \\
(\%)\end{array}$ & $\begin{array}{c}\text { Maximum } \\
\text { Contraction } \\
(\%)\end{array}$ & $\begin{array}{c}\text { Milatation } \\
(\%)\end{array}$ \\
\hline Coal A & 9.1 & 24.0 & 32.0 & 1.22 & 25 & 107 \\
Coal B & 9.9 & 20.1 & 32.1 & 1.59 & 24 & -4 \\
Coal C & 9.6 & 36.5 & 17.6 & 0.73 & 27 & -2 \\
\hline
\end{tabular}

lar weights in the range 152.19-394.77 g/mol were used, the these included carbazole, acridine, 7,8-benzoquinoline, anthraquinone and octacosane. Carbazole, acridine and 7,8-benzoquinoline were used as aromatic hydrocarbons containing nitrogen, anthraquinone as an aromatic hydrocarbons containing oxygen, and octacosane as an aliphatic hydrocarbon. For comparison, coal tar pitch (includes 5\% of quinolone insoluble and $9 \%$ of toluene insoluble) was also used.

\subsection{Dilatometer Test}

According to the dilatometer test of JIS M8801, the softening temperature, maximum contraction temperature, resolidification temperature, contraction, dilatation, and maximum dilatation of coal with additive $\left(\mathrm{MD}_{\text {additive }}\right)$ were measured. The coal samples were crushed to lower than $150 \mu \mathrm{m}$ in diameter, and the powdered hydrocarbon reagents with diameters less than $74 \mu \mathrm{m}$ were added by $1 \mathrm{wt} \%$ of coal. Because the viscosity of coal tar pitch is high at room temperature, coal tar pitch was heated up to $130^{\circ} \mathrm{C}$ to reduce the viscosity before it was added to and mixed with the coal. When coronene was used as the reagent, the maximum dilatation (MD) obtained with the addition of $3 \mathrm{wt} \%$ of coronene was also measured. In addition, the maximum dilatation of coal only $\left(\mathrm{MD}_{\text {coal }}\right)$ was also measured. The difference in the maximum dilatation $(\Delta \mathrm{MD})$ was calculated by subtracting $\mathrm{MD}_{\text {coal }}$ from $\mathrm{MD}_{\text {additive }}$.

$$
\Delta \mathrm{MD}=\mathrm{MD}_{\text {additive }}-\mathrm{MD}_{\text {coal }}
$$

\subsection{Thermogravimetric Analysis}

To investigate the release of volatile matter during carbonization, the weight losses of the samples were measured using a thermogravimeter (Rigaku Corporation, Thermo plus EVO2 TG-DTA). The samples were maintained at $25^{\circ} \mathrm{C}$ for $30 \mathrm{~min}$ in a nitrogen atmosphere, and then heated to $105^{\circ} \mathrm{C}$ at a heating rate of $5^{\circ} \mathrm{C} / \mathrm{min}$, and maintained at that temperature for $1 \mathrm{~h}$. Next, they were heated to $1000^{\circ} \mathrm{C}$ at a heating rate of $5^{\circ} \mathrm{C} / \mathrm{min}$, and the decrease in the weight of each sample was measured. As the samples, only coal, only a hydrocarbon reagent, and coal with a hydrocarbon reagent were used. The coal particles and hydrocarbon reagent were crushed to diameters lower than $150 \mu \mathrm{m}$ and $74 \mu \mathrm{m}$, respectively. In the case of samples that were only a hydrocarbon reagent, pyrene, coronene, and anthraquinone were used. In the case of use of coal with a hydrocarbon reagent, the reagent was mixed in a coal to hydrocarbon weight ratio of 9:1 (coal: hydrocarbon). The amount of the sample was about $10 \mathrm{mg}$. 
ISIJ International, Vol. 59 (2019), No. 8

Table 2. Characteristics of aromatic and aliphatic hydrocarbon reagents.

\begin{tabular}{|c|c|c|c|c|c|}
\hline No. & Name & $\begin{array}{l}\text { Chemical } \\
\text { formula }\end{array}$ & $\begin{array}{l}\text { Molecular weight } \\
\qquad(\mathrm{g} / \mathrm{mol})\end{array}$ & $\begin{array}{l}\text { Melting point } \\
\quad\left({ }^{\circ} \mathrm{C}\right)\end{array}$ & $\begin{array}{l}\text { Boiling point } \\
\left({ }^{\circ} \mathrm{C}\right)\end{array}$ \\
\hline 1 & Acenapthylene & $\mathrm{C}_{12} \mathrm{H}_{8}$ & 152.19 & 89 & 275 \\
\hline 2 & Acenaphthene & $\mathrm{C}_{12} \mathrm{H}_{10}$ & 154.21 & 94 & 277 \\
\hline 3 & Fluorene & $\mathrm{C}_{13} \mathrm{H}_{10}$ & 166.22 & 116 & 298 \\
\hline 4 & Anthracene & $\mathrm{C}_{14} \mathrm{H}_{10}$ & 178.23 & 99 & 338 \\
\hline 5 & Phenanthrene & $\mathrm{C}_{14} \mathrm{H}_{10}$ & 178.23 & 217 & 341 \\
\hline 6 & 9,10-Dihydroanthracene & $\mathrm{C}_{14} \mathrm{H}_{12}$ & 180.25 & 108 & 313 \\
\hline 7 & 9,10-Dihydrophenanthrene & $\mathrm{C}_{14} \mathrm{H}_{12}$ & 180.25 & 108 & 312 \\
\hline 8 & 1-Methylphenanthrene & $\mathrm{C}_{15} \mathrm{H}_{12}$ & 192.26 & & 360 \\
\hline 9 & Fluoranthene & $\mathrm{C}_{16} \mathrm{H}_{10}$ & 202.26 & 153 & 394 \\
\hline 10 & Pyrene & $\mathrm{C}_{16} \mathrm{H}_{10}$ & 202.26 & 110 & 384 \\
\hline 11 & 1,2-Benzanthracene & $\mathrm{C}_{18} \mathrm{H}_{12}$ & 228.29 & 160 & 438 \\
\hline 12 & Triphenylene & $\mathrm{C}_{18} \mathrm{H}_{12}$ & 228.29 & 198 & 438 \\
\hline 13 & Perylene & $\mathrm{C}_{20} \mathrm{H}_{12}$ & 252.32 & 270 & 460 \\
\hline 14 & 9,10-Dimethyl-1,2- benzanthracene & $\mathrm{C}_{20} \mathrm{H}_{16}$ & 256.35 & 122 & \\
\hline 15 & 1,2-Benzoperylene & $\mathrm{C}_{22} \mathrm{H}_{12}$ & 276.34 & 281 & 500 \\
\hline 16 & 1,2;3,4-Dibenzanthracene & $\mathrm{C}_{22} \mathrm{H}_{14}$ & 278.35 & 205 & 518 \\
\hline 17 & 1,2;5,6-Dibenzanthracene & $\mathrm{C}_{22} \mathrm{H}_{14}$ & 278.35 & 262 & 524 \\
\hline 18 & Coronene & $\mathrm{C}_{24} \mathrm{H}_{12}$ & 300.36 & 442 & 525 \\
\hline 19 & 1,2;6,7-Dibenzopyrene & $\mathrm{C}_{24} \mathrm{H}_{14}$ & 302.38 & & \\
\hline 20 & 1,2;8,9-Dibenzopentacene & $\mathrm{C}_{30} \mathrm{H}_{18}$ & 378.47 & & \\
\hline 21 & Carbazole & $\mathrm{C}_{12} \mathrm{H}_{9} \mathrm{~N}$ & 167.21 & 247 & 356 \\
\hline 22 & Acridine & $\mathrm{C}_{13} \mathrm{H}_{9} \mathrm{~N}$ & 179.22 & 111 & 345 \\
\hline 23 & 7,8-Benzoquinoline & $\mathrm{C}_{13} \mathrm{H}_{9} \mathrm{~N}$ & 179.22 & 48 & 350 \\
\hline 24 & Anthraquinone & $\mathrm{C}_{14} \mathrm{H}_{8} \mathrm{O}_{2}$ & 208.22 & 287 & 380 \\
\hline 25 & Octacosane & $\mathrm{C}_{28} \mathrm{H}_{58}$ & 394.77 & 65 & 286 \\
\hline 26 & Corannulene & $\mathrm{C}_{20} \mathrm{H}_{10}$ & 250.30 & 269 & \\
\hline
\end{tabular}
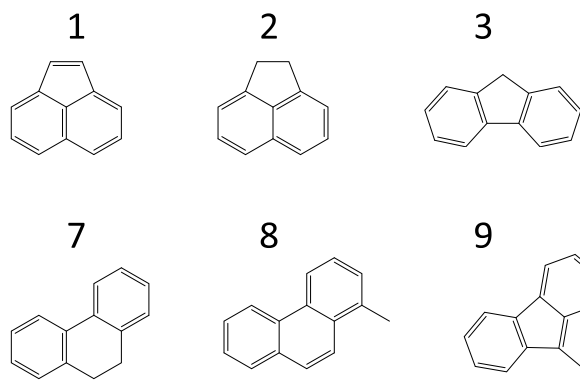

13

14

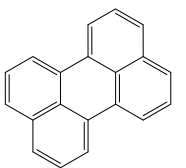

19

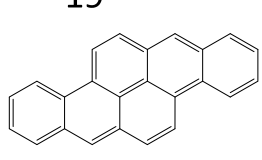

25
9

\section{4}

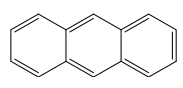

10

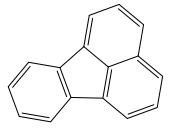

15

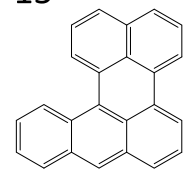<smiles>C1CC2CC3CCC4CC5CCC6CC1C2C6C354</smiles>

16
5

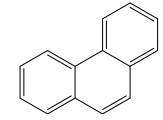<smiles>c1ccc2cc3c(cc2c1)CC1CCCCC1C1CCCCC31</smiles>

6

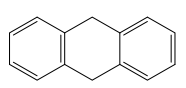

11

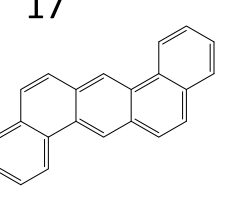

12<smiles>C1=CCC2CC3CC4CCCC4C3CCC2C1</smiles><smiles>C1CCC2C(C1)C1CCCC1C1CCCC21</smiles>

18

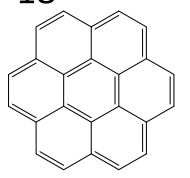

24

23

20

22<smiles>CC1C2CC3CCC(C2)C3C(C)C2CCCCC12</smiles>

Fig. 1. Chemical structure of hydrocarbon. 


\subsection{High-Temperature IR Spectrophotometer}

An IR spectrophotometer (JASCO Corporation, Herschel FT/IR-610 and Irtron IRT-30 microscopic IR attachment) with a heating device for a microscope (LK-600FTIR of Japan High Tech Co., Ltd.) was used to measure the IR absorption spectrum of the heated sample. The details of the equipment were reported in a previous study. ${ }^{26)}$ A potassium bromide $(\mathrm{KBr})$ plate, about $4 \mathrm{~mm} \times 4 \mathrm{~mm} \times 1 \mathrm{~mm}$, was used. Each sample $(10 \mathrm{mg})$ was placed on the plate, and sample tablets, $7 \mathrm{~mm}$ in diameter and about $0.5 \mathrm{~mm}$ thick, were produced by compression. Coal A was used as the samples. Coronene and anthraquinone were used in the case of use of only a hydrocarbon reagent. The hydrocarbon reagents were mixed in a coal to hydrocarbon weight ratio of 9:1 (coal: hydrocarbon) when the sample to be used was coal with a hydrocarbon reagent. The tablets were placed on the heating device with a microscope and maintained at $25^{\circ} \mathrm{C}$ for $30 \mathrm{~min}$ in nitrogen atmosphere. The tablets were then heated to $600^{\circ} \mathrm{C}$ at a heating rate of $5^{\circ} \mathrm{C} / \mathrm{min}$ to measure the IR absorption spectra. The resolution is $4 \mathrm{~cm}^{-1}$ and the scans are 50 times.

\section{Results and Discussion}

\subsection{Dilatation and Interactions between Coal and Hydrocarbon Reagents}

Figure 2 shows the changes in the dilatation of Coal $\mathrm{A}$, and mixtures of Coal $\mathrm{A}$ and $1 \mathrm{wt} \%$ or $3 \mathrm{wt} \%$ of coronene. When $1 \mathrm{wt} \%$ of coronene was added to Coal $\mathrm{A}$, the softening temperature and maximum contraction temperature decreased, but the resolidification temperature hardly changed. The softening temperature and maximum contraction temperature decreased with increase in the proportion of coronene added. The addition of coronene caused the MD of coal to increase. The MD of the mixtures of Coal $\mathrm{A}$ and coronene increased with increase of the proportion of coronene added. Koyano et al. indicated that the tensile strength of coke increased when $3 \mathrm{wt} \%$ of coronene was added to blended coal. ${ }^{27)}$ Based on this previous study, it is inferred that the addition of coronene to blended coal caused the tensile strength of coke to rise because the thermoplastic temperature range and dilatation increased. ${ }^{8,12)}$

The relationship between the values of $\triangle \mathrm{MD}$ and the molecular weights of the hydrocarbon reagents is shown

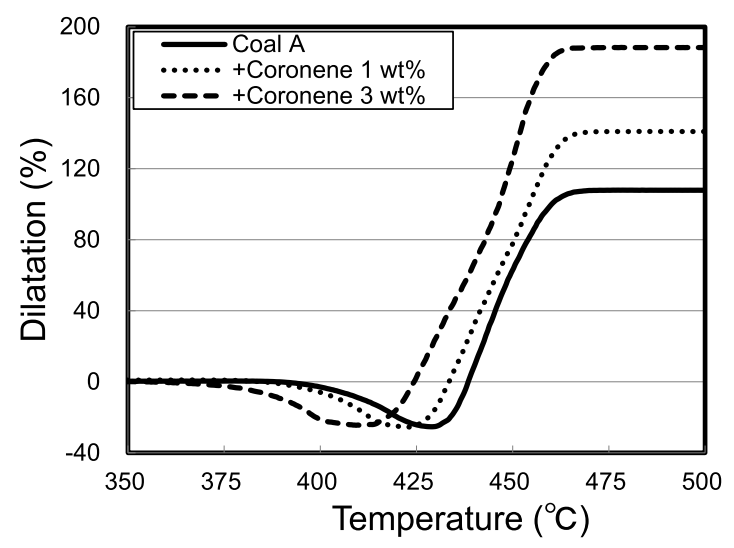

Fig. 2. Temperature dependence of dilatation of coal A with/without coronene. in Fig. 3. The use of a PAH with molecular weight in the range 152.19-178.23 almost unchanged the MD. When a PAH with molecular weight in the range 178.23-252.32 was added to coal, $\triangle \mathrm{MD}$ tended to increase with molecular weight. When a PAH with a molecular weight in the range 252.32-378.47 was added to coal, $\Delta \mathrm{MD}$ tended to increase slightly with decrease in the molecular weight. In previous studies, similar trends were seen in changes in fluidity ${ }^{21)}$ with the addition of a PAH to coal. Hence, it can be inferred that PAHs with molecular weights of 178.23 or higher contributed to the increase in dilatation and fluidity. The $\triangle \mathrm{MD}$ obtained in the case of acridine and 7,8-benzoquinoline was almost the same as that of PAH with a similar molecular weight. The $\triangle \mathrm{MD}$ with carbazole larger than that of PAH with a similar molecular weight. The MD of Coal A with anthraquinone, an aromatic hydrocarbon containing oxygen, decreased. Figure 4 shows the value of $\triangle \mathrm{MD}$ of Coal $\mathrm{A}$ with a PAH and its hydride. When a hydrogenated PAH was added to Coal A, the MD increased much more than when a PAH was added. In a previous study, it was important to thermoplasticity of coal that the transferable hydrogen in coal stabilizes the radical species generated by pyrolysis of coal. ${ }^{28,29)}$ It is inferred that the transferable hydrogens in the ninth and tenth positions of 9,10-dihydrophenanthrene stabilized the radical. Therefore, the transferable hydrogen could inhibit the polymerization of coal and thereby increase its MD greatly. Figure 3 illustrates that the addition of

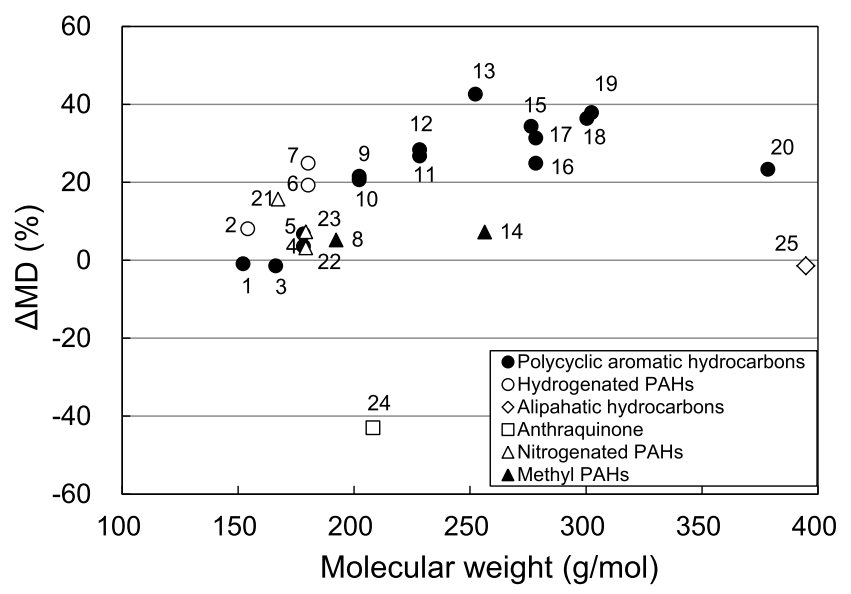

Fig. 3. Relationship between the molecular weight of the added reagent and the $\triangle \mathrm{MD}$ for Coal $\mathrm{A} . \triangle \mathrm{MD}$ : difference in maximum dilatation of coal between non-addition and addition.

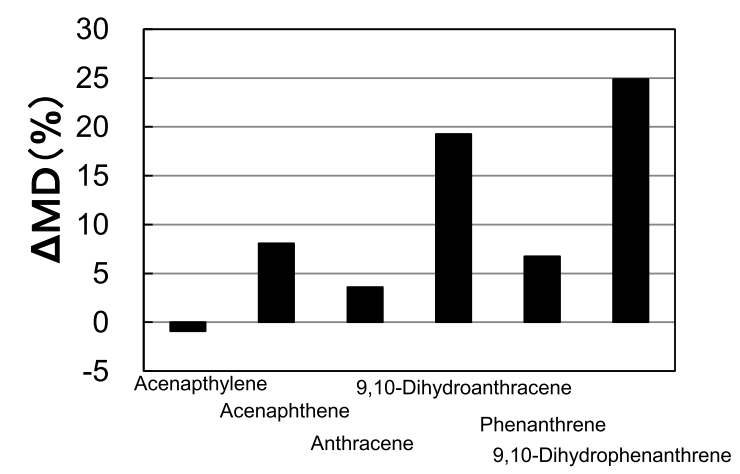

Fig. 4. The $\triangle \mathrm{MD}$ of coal A with polycyclic aromatic hydrocarbons or hydorogenated polycyclic aromatic hydrocarbons. 
octacosane, a linear aliphatic hydrocarbon, hardly changed the MD. A similar tendency was observed in another study in which the addition of an aliphatic hydrocarbon hardly changed the fluidity of coal. ${ }^{21)}$ The coal molecular structure model proposed by Takanohashi et al. ${ }^{30,31)}$ indicated that the molecular structure of bituminous coal was that of a PAH aggregated by intermolecular forces. It is considered that octacosane, an aliphatic hydrocarbon, has low affinity with coal molecules and hence hardly influenced the dilatation properties. $^{27)}$

The influences of PAHs, with and without an aliphatic side chain, were compared. Figure 5 shows the values of $\triangle \mathrm{MD}$ when 1,2-benzanthracene or 9,10-dimethyl1,2-benzanthracene was added to Coal A. The $\Delta \mathrm{MD}$ of the mixture of Coal A and 9,10-dimethyl-1,2-benzanthracene was less than that of the mixture of Coal A and 1,2-benzanthracene. 1,2-benzanthracene has a planar structure and likely easily penetrated the aggregated structure of coal. On the other hand, 9,10-dimethyl-1,2-benzanthracene has a non-planar structure and would not easily penetrate due to steric effects, leading to an decrease in $\triangle \mathrm{MD}$. To investigate the effect of the planar structure on MD, the additions of planar-structured coronene (molecular weight $300.36 \mathrm{~g} / \mathrm{mol}$ ) and non-planar-structured corannulene (molecular weight $250.30 \mathrm{~g} / \mathrm{mol}$ ) to Coal B were examined, as shown in Fig. 6. The $\triangle \mathrm{MD}$ of Coal $\mathrm{B}$ with corannulene was lower than that of Coal $\mathrm{B}$ with coronene. $\triangle \mathrm{MD}$ of the mixture of Coal A and perylene (planar-structured, molecular weight $252.32 \mathrm{~g} / \mathrm{mol}$ ) that is almost equal in molecular weight of corannulene was larger than that of the mixture of Coal A and coronene (See Fig. 3). This suggests that PAHs with planar structures may be effective in increasing the MD.

Figure 7 shows the $\triangle \mathrm{MD}$ of Coal A with $1 \mathrm{wt} \%$ of coal tar pitch or coronene. The MD of Coal A with coronene was

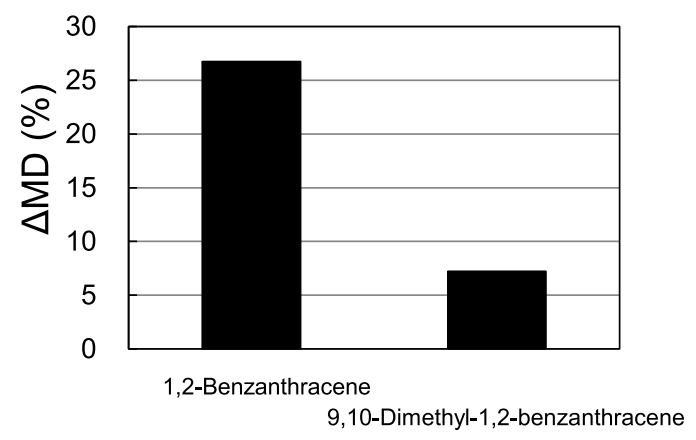

Fig. 5. The $\triangle \mathrm{MD}$ of coal $\mathrm{A}$ with 1,2-Benzanthrance or 9,10-Dimethyl-1,2-benzanthracene.

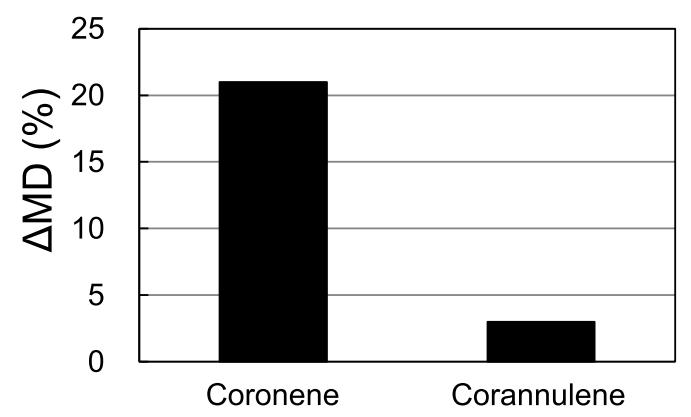

Fig. 6. The $\Delta \mathrm{MD}$ of coal $\mathrm{B}$ with coronene or corannulene. higher than that with coal tar pitch. Coal tar pitch contains numerous hydrocarbons, ${ }^{20}$ those that effectively increased the $\mathrm{MD}$, such as coronene, those that hardly contribute to increase in $\mathrm{MD}$, such as PAHs with molecular weights in the range 152.19-178.23, and those that decreased the MD, such as PAHs containing oxygen. Since coal tar pitch contains an effective component, an ineffective component and an inhibitory component in $\mathrm{MD}$, it is considered that the increase in MD when coronene was added was higher than when coal tar pitch was added.

To investigate the effect of coal type on the change in dilatation of coal by the addition of a hydrocarbon reagent, the changes in the dilatation of Coal A (hard coking coal) and Coal $\mathrm{C}$ (semi-soft coking coal) with the addition of anthraquinone or coronene are discussed. Figure 8 indicates that the MD values of Coal A and Coal $\mathrm{C}$ decreased with the addition of anthraquinone, but the softening temperature, maximum contraction temperature, and resolidification temperature hardly changed. By contrast, the softening temperatures and maximum contraction temperatures of Coal A and Coal C decreased with the addition of coronene, the resolidification temperatures hardly changed, and the MD values increased. In previous studies, when the semi-soft coking coal is added to hard coking coal, semisoft coking coal inhibits the dilatation of hard coking coal because of the difference of thermoplastic temperature range. ${ }^{12,32)}$ The expansion of the thermoplastic temperature ranges of Coal $\mathrm{A}$ and Coal $\mathrm{C}$ by additive is considered a phenomenon favorable to the adhesion of coal particles in the process of carbonization. ${ }^{9)}$ Furthermore, the $\triangle \mathrm{MD}$ of

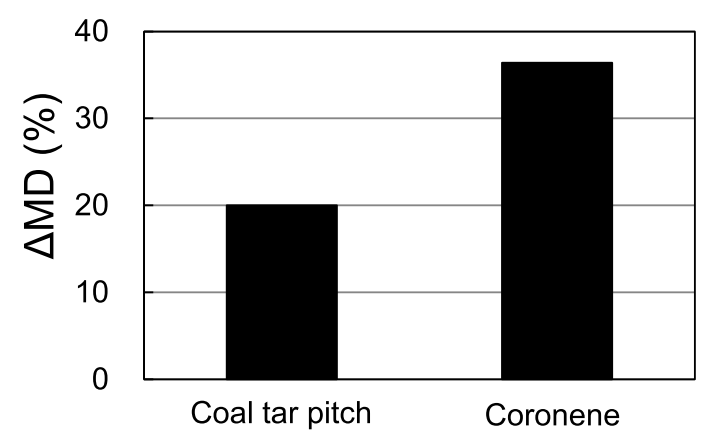

Fig. 7. The $\Delta \mathrm{MD}$ of coal A with coal tar pitch or coronene.

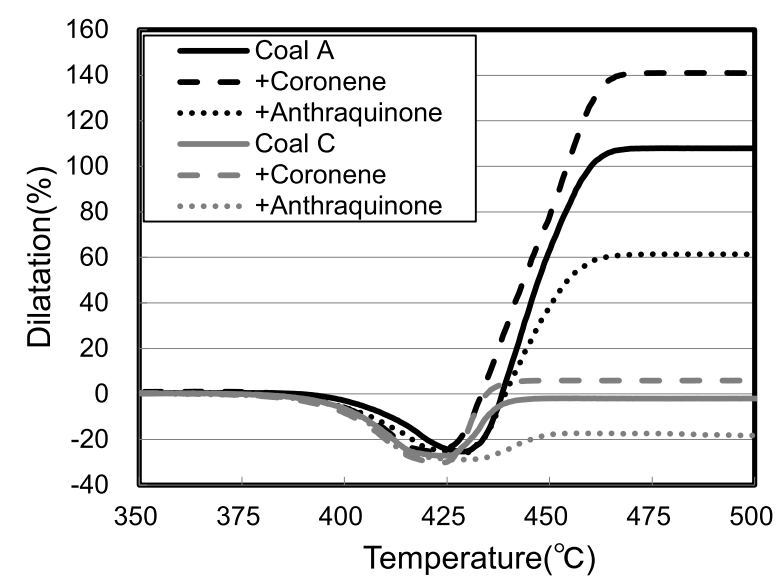

Fig. 8. Temperature dependence of dilatation to two different coal samples with/without coronene or anthraquinone. 
Coal $\mathrm{A}(\mathrm{MD}=107 \%)$ with coronene was larger than that of Coal $\mathrm{C}(\mathrm{MD}=-2 \%)$ with coronene. This is similar to the trends observed in previous studies in which coal tar pitch was added to the coal blends. ${ }^{9,10)}$ The increase of dilatation of high-dilatation coal blends by using additive was larger than that of low-dilatation coal blends by using additive. ${ }^{9,10)}$

\subsection{Thermal Decomposition Characteristics}

The temperature range where coal and hydrocarbon reagents react was investigated. Figure 9 shows the relations between the boiling points of hydrocarbon reagents added to Coal $\mathrm{A}$ and $\triangle \mathrm{MD}$ values. The $\triangle \mathrm{MD}$ of Coal $\mathrm{A}$ with a hydrocarbon reagent increased with an increase in the boiling points of the hydrocarbon reagents. Although the MD of Coal A with pyrene increased, that of Coal A with anthraquinone decreased. The boiling points of pyrene and anthraquinone are lower than the thermoplastic temperature of Coal A. These indicate that pyrene and anthraquinone react with coal at temperatures below the thermoplastic temperature range or that pyrene and anthraquinone when coexisting with the coal, do not volatilize until the temperature reaches the thermoplastic temperature range of the coal, and react with the coal in this range.

To examine the temperature range in which coal reacts with the hydrocarbon reagents, the changes in weight with temperature were measured. Figures $\mathbf{1 0}$ to $\mathbf{1 2}$ show the changes in the weight of each reagent. That calculated values were defined as the arithmetical mean of weight decrease of coal and that of hydrocarbon reagent. The weight of pyrene decreased at a temperature lower than its boiling point of $384^{\circ} \mathrm{C}$ in Fig. 10. The measured decrease in the weight of a mixture in the temperature range of $150^{\circ} \mathrm{C}$ to $270^{\circ} \mathrm{C}$ was larger than the calculated value. Above $270^{\circ} \mathrm{C}$, the measured values were almost the same as the calculated values. This is likely because pyrene completely volatilized below $270^{\circ} \mathrm{C}$ when only pyrene was used as the sample. The temperature at which pyrene completely volatilized below $230^{\circ} \mathrm{C}$ when pyrene added to coal was used as the sample. It is considered that pyrene reacted with coal at a temperature lower than the thermoplastic temperature of the coal and the dilatation increased in the thermoplastic temperature range. The bituminous coal is considered an agglomeration of continuously distributed molecules from low molecular weight

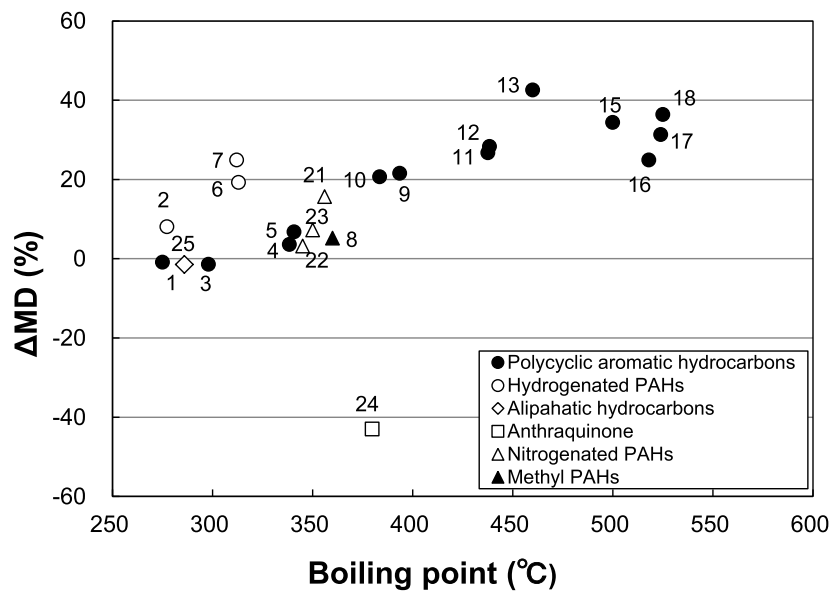

Fig. 9. Relationship between the boiling point of the added reagent and the $\triangle \mathrm{MD}$. components to high molecular weight ones. ${ }^{31)}$ The occurrence of coal softening can be explained on the basis of the solution of high molecular components in low molecular weight components. ${ }^{31)}$ Saito et al. ${ }^{33)}$ observed a change in mobility of coal by using the in situ NMR imaging technique, and reported that as the temperature was increased in the range $300-425^{\circ} \mathrm{C}$, the mobile components gradually

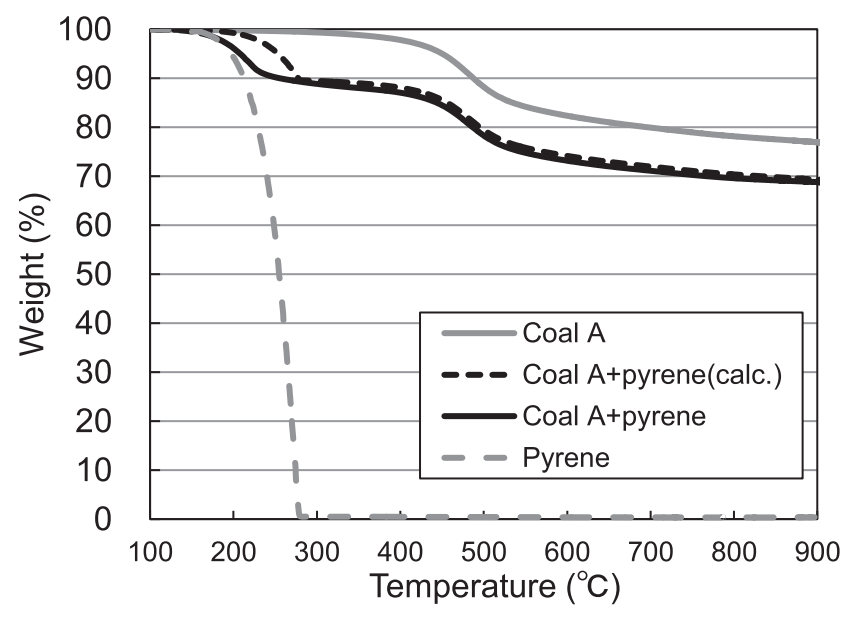

Fig. 10. Temperature dependence of coal A samples weight of coal A, pyrene and coal A + pyrene.

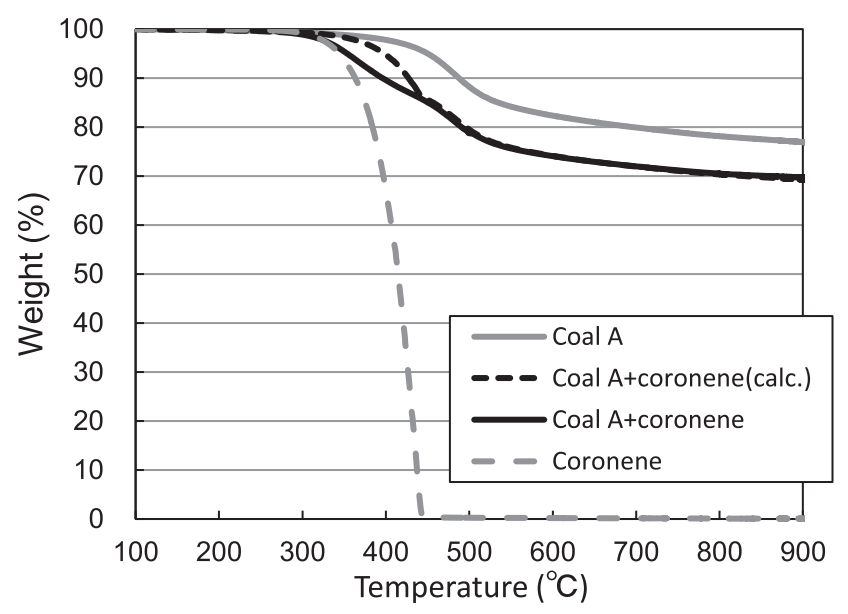

Fig. 11. Temperature dependence of sample weight of coal A, coronene and coal A + coronene.

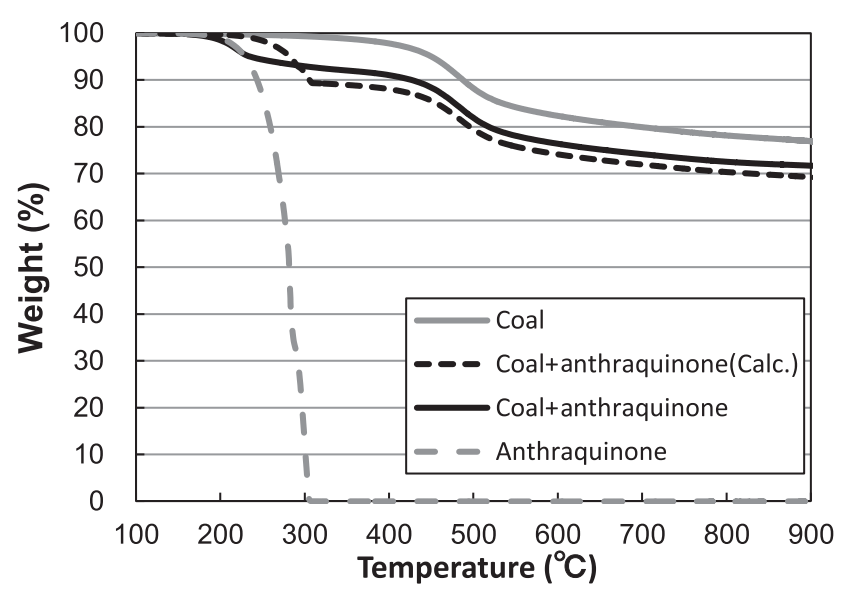

Fig. 12. Temperature dependence of sample weight of coal A, anthraquinone and coal $\mathrm{A}+$ anthraquinone. 
increased around the initial mobile components present at $25^{\circ} \mathrm{C}$. Saito et $a l^{33)}$ reported that the mobile components of hard coking coal are larger than that of semi-soft coking coal. With the addition of pyrene, some of the molecules of coal likely melt into molten pyrene during heating, increasing mobile component. The increase in the dilatation of coal due to the addition of pyrene is thought to be caused by the increase in the quantity of mobile components.

As shown in Fig. 11, when a mixture of coal and coronene was used, whose effect on $\triangle \mathrm{MD}$ was larger than pyrene, the measured decreases in weight were larger than the calculated values in temperature range of $310^{\circ} \mathrm{C}$ to $440^{\circ} \mathrm{C}$. The measured and calculated values were almost the same above $440^{\circ} \mathrm{C}$. Therefore it is considered that coronene almost completely volatilized until lower than $440^{\circ} \mathrm{C}$. The temperatures at which coronene completely volatilized and the temperature at which coronene added to coal completely volatilized were almost equal. The boiling point of coronene is $525^{\circ} \mathrm{C}$ and $70 \mathrm{wt} \%$ or more of coronene survived at $395^{\circ} \mathrm{C}$, at which temperature Coal A started to soften. The $20 \mathrm{wt} \%$ or more of coronene remained at $429^{\circ} \mathrm{C}$, the maximum contraction temperature of Coal A. Koyano et $a l .{ }^{27)}$ reported that if molecular weight of additive is larger, its boiling point is higher, and much more fraction of polyaromatic hydrocarbons should contribute to co-fusing. As a result, the additive improves the coal plastic property. Based on these results, it is considered that coronene reacted with coal in a temperature range wider than that of pyrene and, as a result, the $\triangle \mathrm{MD}$ obtained with the addition of coronene was larger than that obtained with the addition of pyrene. It is considered from these that molten coronene was hard to volatilize during heating, and that the amount of mobile component increased greatly because the coal molecule dissolved more in molten coronene, increasing mobile component. As a result, $\triangle \mathrm{MD}$ of coronene increased.

As shown in Fig. 12, the measured decrease in the weight of a mixture of coal and anthraquinone, whose effect on $\triangle \mathrm{MD}$ was negative, was larger than the calculated value in the temperature range of $200^{\circ} \mathrm{C}$ to $300^{\circ} \mathrm{C}$. Above $300^{\circ} \mathrm{C}$, the measured decrease in weight was less than the calculated value. These indicate that a part of anthraquinone, by coexisting with the coal, did not volatilize but carbonized with the coal later. The reactions of thermal decomposition and polymerization compete with each other in the thermoplastic process of coal. ${ }^{28)}$ When the quantity of transferable hydrogen is small, the percentage of thermal polymerization reaction increases. ${ }^{28)}$ Clemens et al. ${ }^{34)}$ observed a change in transferable hydrogen of coal by using the FT-IR, and reported that as the oxidation reaction proceeds, the transferable hydrogen and plastic property gradually decreased. The measured decrease in weight of the mixture was smaller than the calculated decrease above $300^{\circ} \mathrm{C}$. This suggests that the transferable hydrogen in coal was consumed by oxygen from anthraquinone, thereby accelerating reaction of polymerization.

\subsection{High-Temperature IR Absorption Spectrum}

The changes in the structure of coal when a hydrocarbon reagent was added were examined through IR spectrophotometric analysis. Figures $\mathbf{1 3}$ to $\mathbf{1 5}$ show the changes in the IR spectra of each sample. Figure 13 illustrates that, when only coal was used, the aliphatic stretching vibration observed in the range $2960-2850 \mathrm{~cm}^{-1}$ decreased with an increase in temperature. Figure 14 shows the changes with the temperature in the IR absorption spectrum of a mixture of coal and coronene. The peaks at $850 \mathrm{~cm}^{-1}$ and $1300 \mathrm{~cm}^{-1}$ derived from coronene, which were not observed when only coal was used, disappeared at $350^{\circ} \mathrm{C}$. The changes with the temperature in the IR absorption spectrum of a mixture of coal and anthraquinone in Fig. 15 show the disappearance of the peak of $1690 \mathrm{~cm}^{-1}$ derived from anthraquinone at $300^{\circ} \mathrm{C}$. The peaks derived from coronene and anthraquinone disappeared at a temperature lower than the volatilizing temperature of each additive as measured using a thermogravimeter. Although there may be difference of volatilizing temperature between high-temperature FT-IR and thermogravimeter and difference of volatilizing temperature between simple additive and mixture with additive and coal, the results of high-temperature FT-IR suggest that the structure of each additive changed due to interaction with coal during heating.

The ratio of the peak intensity of aromatic stretching vibration, which is observed at around $3050 \mathrm{~cm}^{-1}$, to the

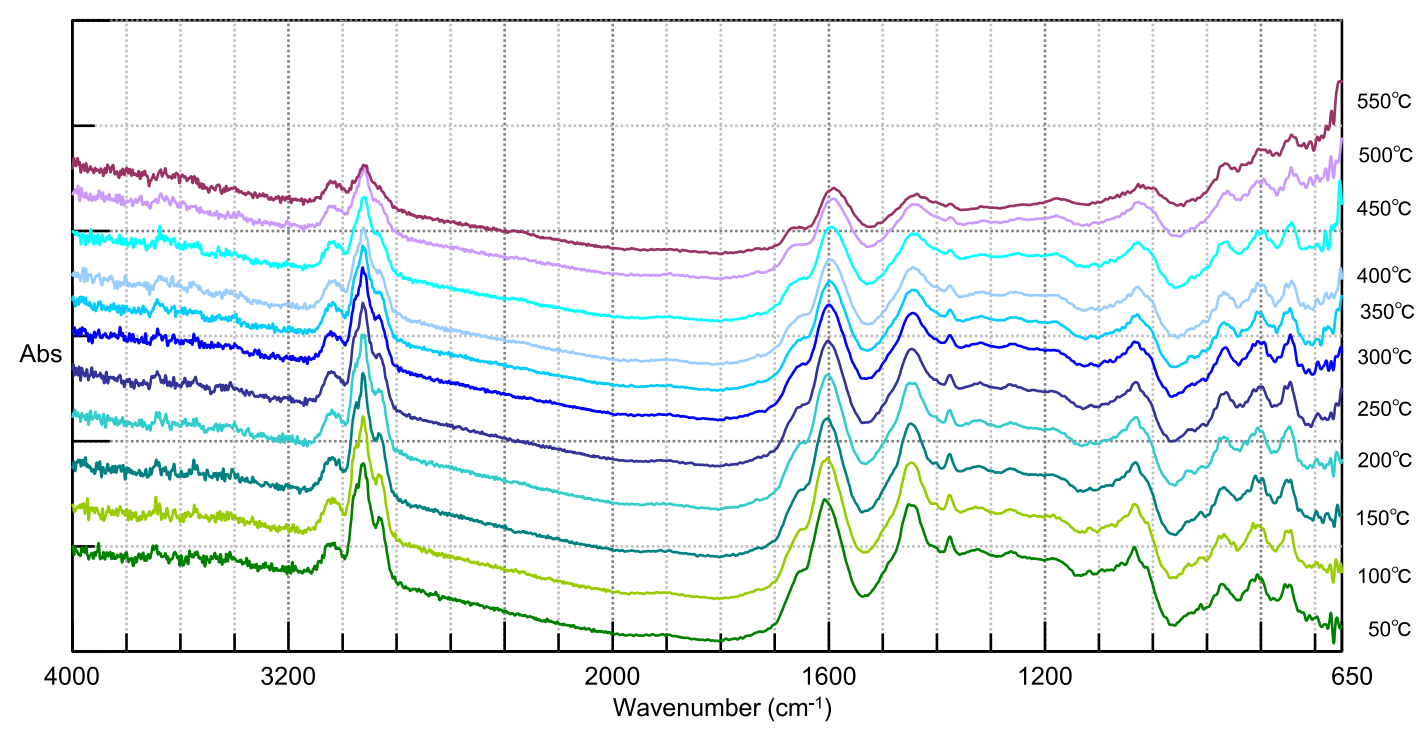

Fig. 13. In situ pyrolysis FT-IR spectra of Coal A. (Online version in color.) 

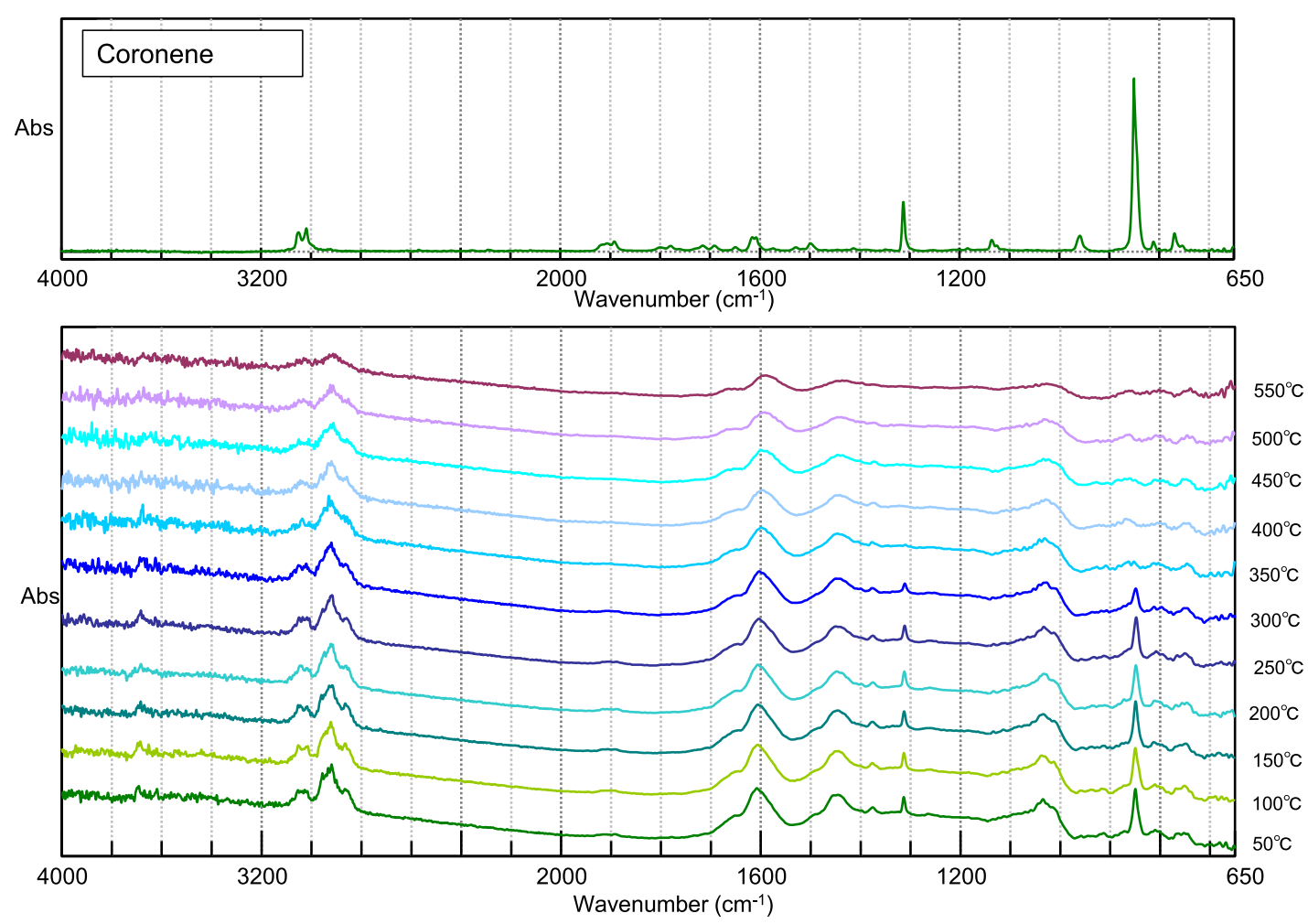

Fig. 14. In situ pyrolysis FT-IR spectra of Coal $\mathrm{A}+$ coronene. (Online version in color.)
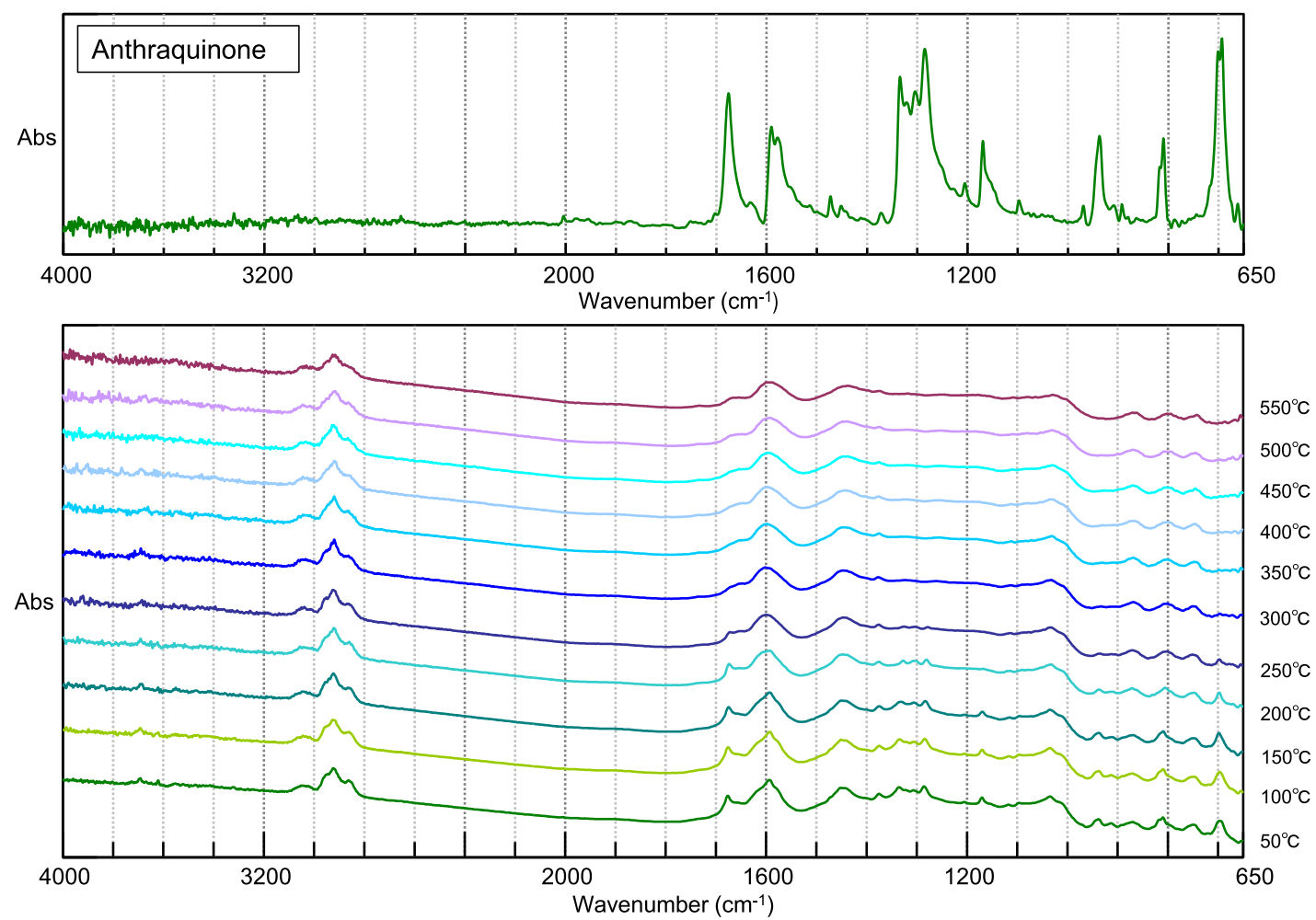

Fig. 15. In situ pyrolysis FT-IR spectra of Coal A + anthraquinone. (Online version in color.)

peak intensity of aliphatic stretching vibration, which is observed in the range $2960-2850 \mathrm{~cm}^{-1}$ on the IR spectrum of coal, merits attention and is used as a simplified index. ${ }^{26)}$ Figure 16 shows changes with the temperature in the peak intensity ratio of aromatic to aliphatic. In the case of coal only, as temperature rose, the peak intensity ratio of aromatic to aliphatic increased. A similar trend was observed in a previous study. ${ }^{26)}$ The ratio of aromatic to aliphatic of coronene added to coal was greater than that of coal below $300^{\circ} \mathrm{C}$. It is because ratio of aromatic to aliphatic of coronene is large. The ratio of aromatic to aliphatic of anthraquinone added to coal was as same as that of coal below $300^{\circ} \mathrm{C}$. It is because there are not peak intensity of anthraquinone at around $3050 \mathrm{~cm}^{-1}$ and in the range $2960-2850 \mathrm{~cm}^{-1}$. In 


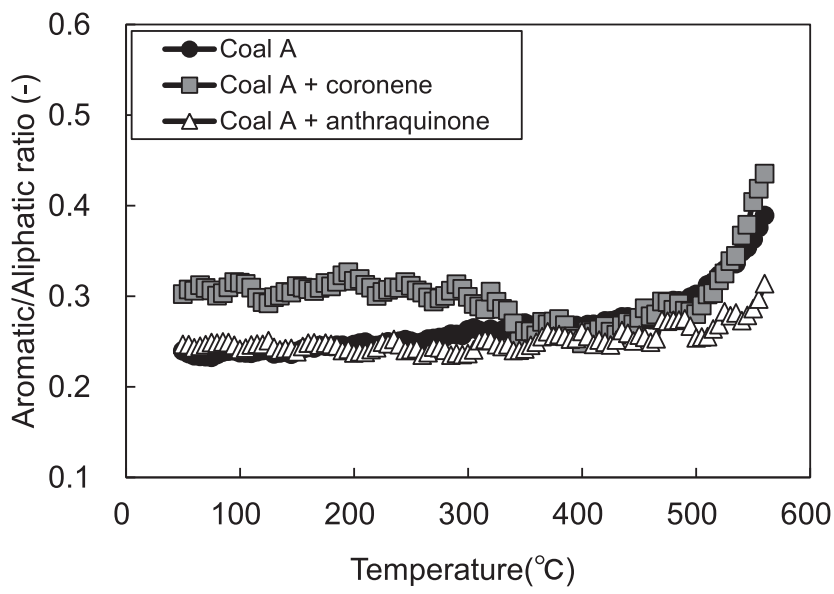

Fig. 16. Temperature dependence of peak intensity ratio (aromatic/ aliphatic $\mathrm{C}-\mathrm{H}$ )

the case of a mixture of coal and coronene, the peak intensity ratio of aromatic to aliphatic decreased as temperature increased from $300^{\circ} \mathrm{C}$ to $350^{\circ} \mathrm{C}$. This behavior is thought to be due to the volatilization of coronene. In addition, in the case of a mixture of coal and coronene, the peak intensity ratio of aromatic to aliphatic at $550^{\circ} \mathrm{C}$ was larger than that of coal at $550^{\circ} \mathrm{C}$. The peak intensity ratio of aromatic to aliphatic of a mixture of coal and anthraquinone at $550^{\circ} \mathrm{C}$ was smaller than that of coal at $550^{\circ} \mathrm{C}$. It has been suggested in a previous study that the change in the peak intensity of aliphatic stretching vibrations during thermal decomposition is related to the change in the thermoplastic behavior of coal. $^{26)}$ It is possible that the change of the dilatation of coal by the additive caused the change of peak intensity ratio of aromatic to aliphatic at $550^{\circ} \mathrm{C}$.

\section{Conclusion}

In this study, the dilatation of coal to which hydrocarbon reagents contained in such as coal tar pitch are added was measured to identify hydrocarbon contributing to an increase in the dilatation and to make clear the mechanism of interaction between the hydrocarbon reagent and coal.

As a result, it was found that the use of a PAH with molecular weight in a range 152.19-178.23 as an additive agent almost unchanged the MD. When a PAH with molecular weight in the range 178.23-378.47 was added to the coal, the MD increased. The increase in the MD of coal with 9,10-dihydrophenanthrene was larger than that with phenanthrene. This is likely because the hydrogen atoms in the ninth and tenth positions in 9,10-dihydrophenanthrene inhibit the polymerization of the coal structure. The MD hardly changed with the addition of a linear aliphatic hydrocarbon $\left(\mathrm{C}_{28} \mathrm{H}_{58}\right)$ and decreased due to the addition of anthraquinone with carbonyl carbon. When a PAH with non-planar structure was added to the coal, the increase in $\mathrm{MD}$ was lower than when a PAH with planar structure was added.

The value of $\triangle \mathrm{MD}$ tended to increase as the boiling points of the hydrocarbon reagents rose. It is considered that hydrocarbon reagents with high boiling points react with coal in a temperature range wider than hydrocarbon reagents of low boiling point.
In the case of a mixture of coal and coronene, whose effect on $\triangle \mathrm{MD}$ was large, the peak intensity ratio of aromatic to aliphatic at $550^{\circ} \mathrm{C}$ was larger than that of coal at $550^{\circ} \mathrm{C}$. Furthermore, in the case of a mixture of coal and anthraquinone, whose effect on $\triangle \mathrm{MD}$ was negative, the peak intensity ratio of aromatic to aliphatic of a mixture of coal and anthraquinone at $550^{\circ} \mathrm{C}$ was lower than that of coal at $550^{\circ} \mathrm{C}$. It is possible that the change of the dilatation of coal by the additive caused the change of peak intensity ratio of aromatic to aliphatic at $550^{\circ} \mathrm{C}$.

\section{REFERENCES}

1) Y. Kubota, S. Nomura, T. Arima and K. Kato: Tetsu-to-Hagané, 96 (2010), 328 (in Japanese).

2) M. Mihashi, M. Soejima, A. Asakuma, T. Yamamoto, H. Aoki, T. Miura, K. Kato and S. Itagaki: Tetsu-to-Hagané, 88 (2002), 188 (in Japanese).

3) N. Andriopulos, C. E. Loo, R. Dukino and S. J. Mcguire: ISIJ Int., 43 (2003), 1528

4) H. Hayashizaki, K. Ueoka, T. Ogata, Y. Yamazaki, Y. Matsushita, H. Aoki, T. Miura, K. Fukuda and K. Matsudaira: Tetsu-to-Hagané, 95 (2009), 460 (in Japanese).

5) H. Hayashizaki, K. Ueoka, M. Kajiyama, Y. Yamazaki, K. Hiraki, Y. Matsushita, H. Aoki, T. Miura, K. Fukuda and K. Matsudaira: Tetsu-to-Hagané, 95 (2009), 593 (in Japanese).

6) Y. Kubota, S. Nomura, T. Arima and K. Kato: Tetsu-to-Hagané, 92 (2006), 833 (in Japanese).

7) T. Arima and Y. Sakurai: CAMP-ISIJ, 11 (1998), 842 (in Japanese).

8) T. Arima: Tetsu-to-Hagané, 87 (2001), 274 (in Japanese).

9) A. Miyagawa, S. Takahashi and S. Ito: J. Fuel Soc. Jpn., 51 (1972), 172 (in Japanese).

10) S. Nomura and T. Arima: Fuel Process. Technol., 159 (2017), 369.

11) I. Minamisawa, N. Okui, T. Yamada, K. Hamamura and S. Kanabara: J. Fuel Soc. Jpn., 59 (1980), 841 (in Japanese).

12) Y. Hayashi, S. Aizawa, K. Uebo, S. Nomura and T. Arima: Tetsu-toHagané, 100 (2014), 118 (in Japanese).

13) T. Nishi, K. Shiraishi, Y. Miura, H. Uematsu and Y. Yone: Tetsu-toHagané, 68 (1982), 2141 (in Japanese).

14) S. B. Choudhury, S. Sarkar, P. K. Chatterjee, S. S. Chateerjee, R. R. Prasad, S. N. Murkherjee, S. K. Ghosh, S. R. K. Rao, A. N. Bose, B. B. Brahmachari and R. Haque: Fuel Process. Technol., 51 (1997), 165.

15) L. Hao, P. Feng, W. Song, W. Lin, S. Yoon and I. Mochida: J. Fuel Chem. Technol., 40 (2012), 1025.

16) C. Chang, T. Whang, D. Huang, D. Wang, S. Tsai and M. Hung: Fuel, 117 (2014), 364.

17) R. Ashida, S. Nagaya, K. Miura, Y. Kubota, Y. Nishibata and A. Kotani: ISIJ Int., 54 (2014), 2432.

18) N. Sakimoto, T. Takanohashi, Y. Harada and H. Fujimoto: ISIJ Int., 54 (2014), 2426.

19) T. Anyashiki, H. Fujimoto, T. Yamamoto, T. Sato, H. Matsuno, M. Sato and K. Takeda: Tetsu-to-Hagané, 101 (2015), 515 (in Japanese).

20) Y. Fujioka and T. Koike: CAMP-ISIJ, 3 (1990), 566 (in Japanese).

21) Y. Fujioka, K. Saito and K. Kato: Proc. Conf. Coal Sci., 43 (2006), 119 (in Japanese).

22) Y. Maeda and K. Hanada: CAMP-ISIJ, 27 (2014), 632, CD-ROM (in Japanese).

23) N. Tsubouchi, Y. Mochizuki, Y. Ono, K. Uebo, T. Takanohashi and N. Sakimoto: ISIJ Int., 54 (2014), 2439.

24) H. Otsuka, Y. Dohi, T. Matsui and K. Hanada: CAMP-ISIJ, 31 (2018), 614, CD-ROM (in Japanese).

25) N. Tsubouchi, Y. Mochizuki, R. Naganuma, K. Kamiya, M. Nishio, Y. Ono and K. Uebo: Energy Fuel., 30 (2016), 2095.

26) Y. Fujioka, M. Nishifuji, K. Saito and K. Kato: Tetsu-to-Hagané, 88 (2002), 507 (in Japanese).

27) K. Koyano, K. Ueoka, T. Takanohashi, K. Fukada and K. Ota: Tetsuto-Hagané, 96 (2010), 224 (in Japanese).

28) T. Yokono, T. Obara, S. Iyama, J. Yamada and Y. Sanada: J. Fuel Soc. Jpn., 63 (1984), 239 (in Japanese).

29) M. Nomura, S. Murata, K. Kidena and T. Chikada: Tetsu-to-Hagané, 82 (1996), 361 (in Japanese).

30) T. Takanohashi and K. Nakamura: Energy Fuel., 16 (2002), 379.

31) T. Takanohashi, T. Yoshida, M. Iino, K. Kato and K. Fukada: Tetsuto-Hagané, 82 (1996), 366 (in Japanese).

32) T. Arima, S. Nomura and K. Fukuda: Tetsu-to-Hagané, 82 (1996), 409 (in Japanese).

33) K. Saito, I. Komaki, K. Hasegawa and H. Tsuno: Fuel, 79 (2000), 405.

34) A. H. Clemens and T. W. Matheson: Fuel, 74 (1995), 57. 